\title{
Wave-Induced Sediment Transport and Onshore Sandbar Migration
}

\author{
Tian-Jian Hsu \\ University of Florida, Gainesville, Florida, USA \\ Steve Elgar \\ Woods Hole Oceanographic Institution, Wood Hole, Massachusetts, USA \\ R.T. Guza \\ Scripps Institution of Oceanography, La Jolla, California, USA
}

\begin{abstract}
The 25-m onshore migration of a nearshore sandbar observed over a 5-day period near Duck, NC is simulated with a simplified, computationally efficient, wave-resolving singlephase model. The modeled sediment transport is assumed to occur close to the seabed and to be in phase with the bottom stress. Neglected intergranular stresses and fluid-granular interactions, likely important in concentrated flow, are compensated for with an elevated (relative to that appropriate for a clear fluid) model roughness height that gives the best fit to the observed bar migration. Model results suggest that when mean-current-induced transport is small, wave-induced transport leads to the observed onshore bar migration. Based on the results from the simplified phase-resolving model, a wave-averaged, energetics-type model (e.g., only moments of the near-bottom velocity field are required) with different friction factors for oscillatory and mean flows is developed that also predicts the observed bar migration. Although the assumptions underlying the models differ, the similarity of model results precludes determination of the dominant mechanisms of sediment transport during onshore bar migration.
\end{abstract}

Keywords: sediment transport, sandbar migration, wave boundary layer, roughness, bottom stress. 


\section{Introduction}

When mean currents are weak, nearshore sediment transport is driven predominately by waveorbital velocities. As waves shoal, their shapes become skewed (relatively sharp crests and broad, flat troughs) and asymmetric (pitched-forward, with steep front faces and gently sloping rear faces). During the passage of the steep front faces of asymmetric waves, fluid is accelerated strongly as the orbital velocity rapidly changes from maximum offshore to maximum onshore (e.g., Elgar et al., 1988). Sediment transport associated with nonsymmetrical waves often is parameterized with statistics of the near-bottom velocity field averaged over many wave periods. In particular, the skewness (normalized mean cube) of time series of cross-shore fluid velocity (Bowen, 1980; Bailard, 1981) and of cross-shore velocity acceleration (Drake and Calantoni, 2001) have been incorporated into energetics-type (after Bagnold, 1966) models for nearshore sediment transport (Roelvink and Stive, 1989; Nairn and Southgate, 1993; Thornton et al., 1996; Gallagher et al., 1998; Crawford and Hay, 2001; Hoefel and Elgar, 2003; and others). The corresponding morphological evolution is determined from the conservation of sediment mass (i.e., from the cross-shore divergence of the net cross-shore sediment transport rate). Energetics models, driven with moments of time series of fluid velocities measured above the bottom boundary layer, suggest that offshore bar migration, observed when incident waves are energetic, is driven by strong offshoredirected mean currents that are maximum near the bar crest (Thornton et al., 1996; Gallagher et al., 1998). An energetics model extended to include sediment transport associated with the strong flow accelerations under steep wave faces (Hoefel and Elgar, 2003, hereinafter the extended-energeticsacceleration EEA model) suggests that onshore bar migration, observed when incident wave energy is moderate and mean currents are relatively weak, is related to cross-shore gradients in the skewness of velocity accelerations. 
In the energetics models, the stress on the seabed and the resulting sediment transport are related to moments of velocity and acceleration via power laws with empirical coefficients. The velocity, bottom stress, and sediment transport are all in phase. Other models predict a phase lag between flow forcing and bottom stress, and between stress and transport. For example, transport of sediment suspended high above the bed is not in phase with free-stream wave-orbital velocities nor with the bottom stress, and usually is modeled by solving an advection-diffusion equation for sediment concentration (e.g., Li and Davies, 1996; Henderson et al., 2004; Hsu and Liu, 2004). Dilute suspensions often are simulated by single-phase (clear fluid only) models that neglect intergranular stresses and fluid-granular interactions. In flows with dense concentrations of grains, such as near the bed, a two-phase (fluid and sediment) approach may be required to model fluid-sediment and grain-grain interactions (e.g., Dong and Zhang, 2002; Hsu et al., 2004).

A single-phase, wave-resolving eddy-diffusive (WRED) model incorporating suspended sediment transport for which the upward sediment flux just above the bed is given by an empirical reference concentration, and suspended concentrations higher in the water column are determined by turbulent diffusion, simulates sandbar migration with skill close to that of the EEA model (Henderson et al., 2004). Similar to the EEA model, offshore bar migration is caused primarily by offshore-directed mean currents that are maximum near the bar crest. Onshore bar migration is driven by gradients in Stokes' drift, and by coupling between orbital velocities and sediment concentration. During onshore bar migration, the contribution to nearbed transport from velocity skewness is roughly twice that from velocity asymmetry, whereas in the EEA model transport is driven by acceleration skewness, which is proportional to velocity asymmetry. In contrast to the computationally-efficient EEA model, the WRED model is driven with time series of velocities, and is computationally expensive. 
The phase-resolving sediment transport models developed here are different than the energetics, EEA, and WRED models. Turbulence modeling of the wave boundary layer is used to relate the free-stream velocity to the bottom stress, rather than the parameterized relationships of energetics and EEA models. The boundary layer dynamics and turbulent closures are similar to those used in the WRED model, but sediment transport is assumed to be in phase with the bottom stress via an empirical Meyer-Peter Mueller-type power law.

Here, observations of onshore sandbar migration are compared with predictions based on waveresolving and wave-averaged sediment transport models. In three different wave-resolving models, the bottom stress is represented with a quasi-steady formulation, a first-order (linear) boundary layer, and a computationally expensive second-order model. The bottom stress is then substituted into a sediment transport power law. The wave-averaged models include an energetics-based model and an energetics model extended to account for different friction factors for wave- and mean-flowinduced transport.

Models for wave-induced sediment transport are formulated in section 2, and model-based predictions are compared with observations of onshore bar migration in section 3. A velocity-momentbased energetics model (Bowen, 1980; Bailard, 1981) is modified to include separate friction coefficients for orbital-velocity-only-driven transport, and for transport that involves mean currents (Section 4). The models simulate onshore bar migration with similar skill. 


\section{Wave-Induced Sediment Transport}

\subsection{Model Formulation for Bottom Stress}

\subsubsection{Second-order Boundary Layer Model}

The governing equations for a one-dimensional wave boundary layer model follow from the Reynoldsaveraged Navier-Stokes equations by adopting a boundary layer approximation (i.e., $k_{w} \delta \ll 1$, where $k_{w}$ is the wavenumber and $\delta$ is the boundary layer thickness) and assuming small amplitude waves (i.e., $k_{w} A \ll 1$, where $A$ is the wave amplitude). Retaining the nonlinear terms to second order yields (see Trowbridge and Madsen (1984) and Henderson et al., (2004) for details):

$$
\begin{gathered}
\frac{\partial w}{\partial z}=\frac{1}{c} \frac{\partial u}{\partial t} \\
\frac{\partial u}{\partial t}-\frac{u}{c} \frac{\partial u}{\partial t}+w \frac{\partial u}{\partial z}=\frac{\partial \tilde{U}_{0}}{\partial t}-\frac{\tilde{U}_{0}}{c} \frac{\partial \tilde{U}_{0}}{\partial t}+\frac{1}{\rho} \frac{\partial \tau_{z x}}{\partial z}
\end{gathered}
$$

where $u$ and $w$ are the cross-shore $(x)$ and normal to the bed $(z)$ velocity components, $t$ is time, $\rho$ is the fluid density, $\tau_{z x}$ is the fluid stress, and $\tilde{U}_{0}$ is the oscillatory (wave-orbital, with no mean) velocity. The phase speed of shoreward propagating, linear shallow water waves is $c=\sqrt{g h}$, with $g$ gravitational acceleration and $h$ the water depth.

\subsubsection{First-order Boundary Layer Model}

The second-order boundary layer model can be simplified by retaining only the leading order terms in (1) and (2), resulting in a first-order (linearized) boundary layer equation (e.g., Grant and Madsen, 1979):

$$
\frac{\partial u}{\partial t}=\frac{\partial \tilde{U}_{0}}{\partial t}+\frac{1}{\rho} \frac{\partial \tau_{z x}}{\partial z}
$$


The linearized continuity equation along with the bottom boundary condition gives $w=0$. Boundary layer streaming, included in the second-order model, is neglected.

\subsubsection{Turbulence Closure}

Adopting the eddy viscosity hypothesis (Grant and Madsen, 1979; Justesen, 1988), the fluid stress $\tau_{z x}$ is given by

$$
\tau_{z x}=\rho\left(\nu_{t}+\nu\right) \frac{\partial u}{\partial z},
$$

with $\nu_{t}$ the eddy viscosity and $\nu$ the fluid viscosity. Near the bed, the eddy viscosity $\nu_{t}$ can be approximated using mixing-length theory (Grant and Madsen, 1979):

$$
\nu_{t}=\kappa \sqrt{\frac{\left|\tau_{b}\right|}{\rho}} \min (z, 0.3 l),
$$

where $\kappa=0.41$ is the Karman constant. Details of the relationship between $\nu_{t}$ and the mixing length far from the bed do not affect the near-bed boundary layer flow (Trowbridge and Madsen, 1984). Therefore, to avoid small computational time steps owing to a large eddy viscosity far from the bed, a constant eddy viscosity is used when the mixing length exceeds $30 \%$ of the computational domain height $l$.

Alternatively, a more accurate eddy viscosity is calculated by fluid turbulent kinetic energy $(k)$ and its dissipation rate $(\epsilon)$ :

$$
\nu_{t}=C_{\mu} \frac{k^{2}}{\epsilon} .
$$

The constant $C_{\mu}$, and $k$ and $\epsilon$ are calculated from standard balance equations and coefficients (see for example, Rodi (1993) and Henderson et al. (2004) for details).

Assuming a logarithmic velocity profile (law of the wall) near the bed, the time-varying bottom 
stress is obtained from the model velocity at the first grid point $\Delta z$ above the bed (Justesen, 1988):

$$
\tau_{b}=\rho\left[\frac{\kappa u(\Delta z, t)}{\ln \left(30 \Delta z / K_{s}\right)}\right]^{2} .
$$

The roughness height $K_{s}$ is proportional to the grain diameter $d$ (Appendix). The bottom stress $\tau_{b}$ also serves as the bottom boundary condition for the momentum equations (2) or (3).

\subsubsection{Quasi-steady Parameterization}

An alternative, quasi-steady approach is to estimate the wave-induced instantaneous bottom stress $\tau_{b}(t)$ directly from the instantaneous, oscillatory free-stream velocity through a quadratic dependence (e.g., Ribberink, 1998; Traykovski et al., 1999):

$$
\tau_{b}(t)=\frac{1}{2} \rho f_{w} \tilde{U}_{0}(t)\left|\tilde{U}_{0}(t)\right|
$$

where $f_{w}$ is a wave friction factor. When the root-mean-square wave-orbital velocity is much larger (a factor of 5 for the onshore bar migration discussed below) than mean currents (e.g., undertow), nonlinear wave-current interaction effects on wave-induced bottom stress are weak and can be parameterized by an enhanced wave friction factor (Soulsby et al., 1993).

The quasi-steady formulation (8) is particularly computationally efficient because boundary layer calculations are not required. However, detailed boundary layer processes are neglected, and the underlying assumption that bottom stress is in phase with the free-stream velocity can sometimes lead to substantial errors (e.g., Drake and Calantoni 2001; Nielsen and Callaghan, 2003). For example, over a wave period quasi-steady models erroneously predict zero net bottom stress and transport under idealized sawtooth-shaped (zero skewness, high asymmetry) waves, whereas EEA (Hoefel and Elgar, 2003), two-phase (Hsu and Hanes, 2004), and WRED (Henderson et al., 2004) models predict significant net bottom stress and transport. 


\subsection{Model Formulation for Sediment Transport Rate}

During the low energy wave conditions for the onshore bar migration discussed here, although sometimes megaripples were present (Figure 6 in Gallagher et al. (1998)), visual observations suggested little suspended sediment, consistent with the absence of wave-orbital ripples on the seafloor. Recent detailed measurements of sand transport $(d=0.21 \mathrm{~mm})$ in a U-tube (DohmenJanssen et al., 2002) under nonbreaking surface gravity waves (Dohmen-Janssen and Hanes, 2002; Dohmen-Janssen and Hanes, 2005) suggest that most of the transport is in phase with forcing for grain sizes $(d \approx 0.2 \mathrm{~mm})$ and dominant wave periods $(T>6 \mathrm{sec})$ typical of those considered here. A comprehensive analysis of sheet flow $(d \approx 0.2 \mathrm{~mm}$ ) (Ribberink, 1998) suggests a Meyer-Peter Mueller power law for the nondimensional transport rate, $\Psi=q / \sqrt{(s-1) g d^{3}}$, given by

$$
\Psi=11 \frac{\theta}{|\theta|}[|\theta|-0.05]^{1.65}
$$

where $q$ is the dimensional transport, $\theta=\tau_{b} / \rho(s-1) g d$ is the Shields parameter, and $s$ is the sediment specific gravity. Bottom stress from the three phase-resolving models $(1-2,3$, and 8$)$ is coupled with (9) to predict transport rate.

\subsection{Morphological Change}

Temporal changes in the sand level $z_{b}$ owing to accretion and erosion are determined from the estimated gradient in sediment transport rate and conservation of sediment mass as

$$
\frac{\partial z_{b}}{\partial t}=-\frac{1}{\mu} \frac{\partial Q}{\partial x}
$$

where $\mu=0.7$ is the assumed sediment concentration (packing) within the still bed. The timeaveraged net sediment transport $Q$ is obtained by integrating $q(t)$ over the time-step for which (10) 
is evaluated. Small variations in $\mu$ cause only small variations in the predicted morphology change and best-fit parameters.

\subsection{Numerical Implementation}

The convection-diffusion boundary layer and morphological evolution equations are solved efficiently with a forward-time, central-space, explicit scheme (e.g., Jaluria and Torrance, 1986). The vertical computational domain of the wave boundary layer $(0.18 \mathrm{~m})$ is gridded with $\delta z=0.003 \mathrm{~m}$. Further increasing the height of the computational domain, and decreasing $\delta z$, had negligible effect on the results. The time step $\delta t$ for solving the boundary layer is adjusted dynamically to satisfy the constraint imposed by the convection and diffusion terms (Jaluria and Torrance, 1986).

The vertical morphological change $\left(\partial z_{b} / \partial t\right) \Delta t$ in (10) is estimated on a uniformly spaced $(\Delta x=1$ m) grid by linearly interpolating the predicted net transport rate between the current meter locations (nonuniformly spaced in the cross-shore direction, Figure 1). With the morphology updated every $\Delta t=3 \mathrm{hr}$, vertical changes are a small fraction of the water depth. Numerical experiments with different $\Delta x, \Delta t$, and interpolation schemes suggest the results are not sensitive to the values used here.

\section{Onshore Bar Migration}

The models are tested by comparisons with onshore bar migration observed near Duck, NC (2227 September 1994). The measurements, observational errors, and the assumption of alongshore homogeneity (e.g., divergences of alongshore transport are neglected in (10), based on the similar cross-shore depth profiles observed on nearby transects) are discussed in Gallagher et. al. (1998). 
The models were forced with demeaned (3-hr averages) velocity time series $\tilde{U}_{0}(t)$ measured about $0.5 \mathrm{~m}$ above the seafloor at 11 cross-shore locations extending $250 \mathrm{~m}$ from near the shoreline to approximately 4-m water depth (Figure 1). The calculated instantaneous bottom stress yields the sediment transport rate (9), and the corresponding morphological change (10) is then updated. Results are presented for a spatially constant sand grain diameter $(d=0.20 \mathrm{~mm})$, but are qualitatively similar using the observed values of $d$, which ranged from $0.29 \mathrm{~mm}$ at the shoreline to $0.15 \mathrm{~mm}$ in 4-m water depth. The roughness $K_{s}$ also is assumed to be constant. During the 5-day period modeled, the Shields parameter $\theta$ estimated near the bar crest with the single-phase models often exceeds 0.8 , the nominal lower limit of sheet flow.

To assess model performance, model skill is defined as

$$
M=1-\sqrt{\frac{\sum_{n=1}^{N}\left(\Delta_{n}^{p}-\Delta_{n}\right)^{2}}{\sum_{n=1}^{N} \Delta_{n}^{2}}},
$$

where $\Delta$ and $\Delta^{p}$ are the observed and predicted changes to the seafloor elevation at each of the $N$ measurement points. Perfect predictions have skill $M=1$, and a prediction of no change in the seafloor yields $M=0$.

Both the quasi-steady model (8) with best-fit wave friction factor $f_{w}=0.01(M=0.34$, crosses in Figure 1) and the first-order (linear) boundary layer model (3) with mixing-length closure (6) and roughness $K_{s}=6 d$ ( $M=0.27$, not shown) predict onshore sandbar migration, but the height of the sandbar crest (cross-shore position $=220 \mathrm{~m}$ in Figure 1$)$ is underpredicted. Numerical experiments suggest that better predictions near the bar crest can be obtained at the expense of poorer predictions near the shoreline (cross-shore position 160 meter). Predictions are improved using the more accurate second-order (nonlinear) model (1-2) with both the mixing length $\left(K_{s}=14 d\right.$, $M=0.57$, plusses) and more complete $k-\epsilon\left(K_{s}=25 d, M=0.69\right.$, circles $)$ closures. These results suggest that nonlinear boundary layer processes enhance the shoreward transport of sediment 
near the sandbar crest, consistent with earlier studies (Trowbridge and Young, 1989; Henderson et al., 2004). The best-fit $K_{s}$ for onshore bar migration is larger than usually used in a clear fluid (Appendix, $K_{s} \sim 2 d$, Justesen, 1988), consistent with detailed laboratory measurements of sheet flow (Dohmen-Janssen et al., 2001) and numerical results of a two-phase model (Hsu and Raubenheimer, 2005). Sensitivity analysis suggests that a 5\% change in model skill can be caused by a $10 \%$ change in $f_{w}$ in the quasi-steady model and by a $30 \%$ change in $K_{s}$ in the first- and second-order boundary layer models (mixing length closure).

Demeaned velocities are used in the results shown in Figure 1. Accurate parameterizations of wave-current interactions and current-induced bottom stress are complex (e.g., Grant and Madsen, 1979; Fredsøe, 1984; Soulsby et al., 1993). However, when mean flows are weak (as for the onshore migration event discussed here), nonlinear wave-current interactions are small (Soulsby et al., 1993) and the mean-current-induced bottom stress $\tau_{b c}$ can be parameterized by an enhanced current friction factor $f_{c}$ and a quadratic dependence on the mean velocity $\bar{U}_{0}$ (e.g., Fredsøe, 1984):

$$
\tau_{b c}=\frac{1}{2} \rho f_{c} \bar{U}_{0}\left|\bar{U}_{0}\right|
$$

Using (12) and (9) to estimate the mean-current-induced sediment transport with $f_{c}=0.02$ (a typical value for the surf zone), the predicted beach profiles that include both wave- and mean-currentinduced transport are similar to the profile predicted by wave-induce transport alone (compare circles and crosses in Figure 2). For the same $f_{w}$ and $K_{s}$ used in the predictions shown in Figure 1 , the corresponding model skills when including mean-current-induced transport are $M=0.32$ and $M=0.24$ for quasi-steady and first-order model with mixing length, and $M=0.55$ and $M=0.67$ for the second-order models with mixing length and $k-\epsilon$ closures, respectively. Increasing the mean-current friction factor to $f_{c}=0.04$ results in increased (relative to predictions with $f_{c}=0.02$ and to predictions with wave-induced transport only) erosion near the shoreline 
(Figure 2, cross-shore positions less than about $175 \mathrm{~m}$ ) and underprediction of the height of the bar crest (cross-shore position about $220 \mathrm{~m}$ ). The model results are consistent with prior studies (e.g., Thornton et al., 1996; Gallagher et al., 1998) that suggest offshore directed mean currents (e.g., undertow) cause offshore transport. However, the relatively strong wave-induced transport results in the observed net onshore sandbar migration.

\section{Extended energetics: friction factors}

Substituting (8) into the Meyer-Peter Mueller power law (9) shows that the time-averaged $(\langle\rangle)$ transport $\langle\Psi\rangle \sim\left\langle\left|\tilde{U}_{0}^{2.3}(t)\right| \tilde{U}_{0}(t)\right\rangle$. Thus, for the quasi-steady model, transport depends on the 3.3 power of velocity, between the $U^{3}$ and $U^{4}$ dependence in the terms used in standard energetics models. However, commonly used wave-averaged energetics-based sediment transport models (velocity-based, without fluid accelerations (Bowen, 1980; Bailard, 1981)) do not predict onshore bar migration when the total (mean $\bar{U}_{0}$ and oscillatory $\tilde{U}_{0}$ ) velocity field is used to parameterize wave-induced transport (Roelvink and Stive, 1989; Thornton et al., 1996; Gallagher et al., 1998; Hoefel and Elgar, 2003). Even though the mean velocity $\bar{U}_{0}$ is less than $1 / 5$ of the root-mean-square orbital velocity $\left\langle\tilde{U}_{0}^{2}\right\rangle^{1 / 2}$ during the onshore bar migration investigated here, the contributions to the time-average cubed velocity from mean and oscillatory components (i.e., $\left.\left(\bar{U}_{0}+\tilde{U}_{0}\right)^{3}\right)$ have opposite signs and comparable magnitudes. Thus, when mean cross-shore flows (typically offshore directed and less than about $10 \mathrm{~cm} / \mathrm{s}$ ) are included, values of the mean cube velocity are altered substantially relative to values without means, and the associated sediment transport gradients are not consistent with onshore bar migration (crosses in Figure 3, $M=-0.1$ ).

Previous results suggest that different friction factors should be used for wave- and mean-current- 
induced bottom stresses (e.g., Grant and Madsen, 1979; Fredsøe, 1984; Soulsby et al., 1993; see also Figure 2). Although not cast in terms of friction factors, the WRED model also is consistent with different friction factors for steady and oscillatory flows (Henderson et al., 2004). A modified energetics-type model that separates transport associated only with orbital velocities from transport associated with the mean current (including interaction with the oscillatory current) is given by

$$
Q=K_{w}\left[\frac{\epsilon_{b}}{\tan \phi}\left\langle\left|\overrightarrow{\tilde{U}}_{0}\right|^{2} \tilde{U}_{0}\right\rangle+\frac{\epsilon_{s}}{W_{0}}\left\langle\left|\overrightarrow{\tilde{U}}_{0}\right|^{3} \tilde{U}_{0}\right\rangle\right]+K_{c}\left[\frac{\epsilon_{b}}{\tan \phi}\left\langle\left|\vec{U}_{0}\right|^{2} \bar{U}_{0}\right\rangle+\frac{\epsilon_{s}}{W_{0}}\left\langle\left|\vec{U}_{0}\right|^{3} \bar{U}_{0}\right\rangle\right]
$$

where the friction coefficients from contributions from waves only and from waves combined with mean currents are

$$
K_{w}=\frac{C_{w}}{(s-1) g}, \quad K_{c}=\frac{C_{c}}{(s-1) g}
$$

and $\left|\overrightarrow{\tilde{U}}_{0}\right|$ is the magnitude of the orbital velocity vector, $\left|\vec{U}_{0}\right|$ is the magnitude of the total (orbital and mean) velocity vector, $W_{0}$ is the sediment fall velocity, $\phi$ is the friction angle, and $\epsilon_{b}$ and $\epsilon_{s}$ are numerical coefficients. This extended-energetics-friction-factor model is labeled EEFF. Using typical values (Thornton et al., 1996; Gallagher et al., 1998) of $\epsilon_{b}=0.135, \epsilon_{s}=0.015, \tan \phi=0.63$, $W_{0}=0.025 \mathrm{~cm} / \mathrm{s}$, and $s=2.65$, friction coefficients of $C_{w}=0.0046$ and $C_{c}=0.0053$ are obtained by maximizing EEFF model skill for onshore (September 22 to 27, circles in Figure 3, $M=0.25)$ and offshore (October 10 to 15 , case D in Gallagher et al. (1998), Figure $4, M=0.55$ ) sandbar migration. Although better predictions near the bar crest can be obtained at the expense of poorer predictions near the shoreline, and vice-versa, further tuning of model coefficients was not investigated. Using the coefficients determined from the two bar migration events, the 50-m offshore migration of the sandbar observed during a storm with 4-m high offshore waves (September 1 to 5, case A in Gallagher et al. (1998)) is predicted with similar skill by the EEFF $(M=0.45)$ and the unmodified energetics $(M=0.55)$ models (not shown). 


\section{Discussion}

The results presented here (Figures 1 to 4 ) suggest that the time-integrated spatial divergences of transport that result in onshore bar migration can be simulated approximately with computa-

tionally efficient wave-averaged and wave-resolving models. However, although the assumptions underlying the models differ (Hoefel and Elgar, 2003; Henderson et al. 2004; the present models), the similarity of model results precludes determination of the mechanisms of sediment transport during onshore sandbar migration.

Models with different assumptions may yield similar predictions because each model has at least one parameter that can be tuned to compensate for neglected processes. For example, to fit the observed morphological change, the roughness $K_{s}$ in the boundary layer (single-phase) model is elevated (relative to the roughness used in a clear fluid), compensating for neglected intergranular and fluid-granular interactions (Dohmen-Janssen et al., 2001). Similarly, the best-fit value for the magnitude of reference concentration $\alpha$ in the WRED model differs by about $35 \%$ from values based on field observations in unidirectional flow above river dunes (Smith and McLean, 1977; cited in Henderson et al., 2004). If the magnitudes of bedload and suspended load are correlated, then an elevated value for $\alpha$ might compensate for the neglect of bedload in the WRED model.

Correlation between the different velocity moments that drive sediment transport in each model also may result in similar predictive skill despite different underlying assumptions. For example, velocity asymmetry (important in models that resolve the turbulent boundary layer) and acceleration skewness (used in the EEA model) are closely related (Elgar, 1987), and thus although the underlying assumptions and physical rationales of the EEA and WRED models differ greatly, they predict bar migration (both onshore and offshore) with nearly equal skill (Henderson et al., 2004). 
Similarly, although the EEFF model depends on velocity skewness (Figure 5), but not on velocity asymmetry (Figure 6), its predictions are similar to those of the EEA and WRED models because demeaned-velocity skewness and asymmetry have similar cross-shore variation during onshore bar migration (compare Figure 5 with Figure 6).

\section{Conclusions}

A new computationally-efficient model for wave-driven morphological evolution predicts the onshore migration of a sandbar observed over a 5-day period. The model combines a wave-resolving single-phase boundary layer approach to determining bottom stress with a power-law for near-bed sediment transport that is in phase with the bottom stress. Neglected intergranular stresses and fluid-granular interactions are compensated for with an elevated roughness value. Based on results from the phase-resolving model, a wave-averaged (i.e., only moments of the near-bottom velocity field are required) energetics-type model with different friction factors for oscillatory-onlyand mean-plus-oscillatory-flow-driven transport was developed. The two-friction-factor energetics model predicts the observed onshore bar migration with significantly more skill than obtained with a standard energetics model with one friction factor.

The observed onshore bar migration is predicted with similar skill by the new wave-resolving boundary layer model, a previously developed wave-resolving eddy-diffusive model, and by two different wave-averaged energetics models. Despite their similar results, the assumptions underlying the models differ, ranging from near-bed to suspended load transport, driven by different combinations of fluid velocities and fluid accelerations, suggesting that the comparisons of model predictions with the one observed onshore bar migration event are not sufficient to determine the 
dominant mechanisms of sediment transport.

\section{Appendix: The Roughness Height}

The effects of a rough bottom on the flow predicted by single-phase boundary layer models with turbulence closures usually are parameterized by a roughness height, often taken as $1 \sim 2$ grain diameters (Justesen, 1988). Although single-phase models may be appropriate for flow over fixed, rough beds, additional energy is dissipated via intergranular and fluid-granular interactions in particle-laden flows over a mobile bed. Thus, a larger roughness height is expected when parameterizing the flow velocity profile in sheet flow (Dohmen-Janssen et al., 2001). To confirm this, roughness heights were estimated by matching sediment transport rates measured in U-tube experiments under 2nd-order Stokes wave velocities (Ribberink and Al-Salem, 1994) with rates predicted by the first-order boundary layer model and power law (9). The best-fit roughness heights are greater than the corresponding values $\left(K_{s} \sim 2 d\right)$ in a clear fluid, and increase with increasing free-stream flow velocity and oscillatory period. The magnitude of roughness height also depends on the turbulence closure scheme. The mixing length closure often over-predicts the fluid turbulence and energy dissipation in the oscillatory boundary layer, thus requiring a smaller roughness $\left(K_{s}=14 d\right)$ than the more accurate $k-\epsilon$ closure $\left(K_{s}=25 d\right)$ with the second-order model and the same free-stream flow.

Using Swart's (1974) formula (see also Nielsen (1992), p.25) relating friction and roughness,

$$
f_{w}=\exp \left[-5.997+5.213\left(K_{s} / A\right)^{0.194}\right]
$$

the best-fit friction factor $f_{w}=0.01$ of the quasi-steady model (8) corresponds to $K_{s}=11 d$, where the semi-excursion length $A \sim 2 \mathrm{~m}$ is based on a saturated wave field in 1-m water depth. 
The best-fit values of $K_{s}$ (and $f_{w}$ ) in the quasi-steady model therefore also are larger than those used for a clear fluid. In addition to compensating for the neglected effects of intergranular and fluid-granular interactions, the elevated values of $K_{s}$ (and $f_{w}$ ) may account for neglected nonlinear interactions between mean currents and waves in the boundary layer (Soulsby et al., 1993).

\section{Acknowledgments}

Supported by the Office of Naval Research, the National Science Foundation, the Army Research Office, and the Woods Hole Oceanographic Institution Coastal Ocean Institute. J. Trowbridge,

F. Hoefel, S. Henderson, and B. Raubenheimer provided valuable suggestions and discussions. Woods Hole Oceanographic Institution contribution 11126.

\section{References}

Bagnold, R.A., An approach to the sediment transport problem from general physics. Geological Survey Professional Paper 422-I, 1966.

Bailard, J. A., 1981, An energetics total load sediment transport model for a plane sloping beach. J. Geophys. Res., 86, 10938-10954.

Bowen, A., 1980, Simple models of nearshore sedimentation; beach profiles and longshore bars. The Coastline of Canada, Pap. 80-10, 1-11.

Crawford A.M., \& A.E. Hay, 2001, Linear transition ripple migration and wave orbital velocity skewness: Observations. J. Geophys. Res., 106, 14113-14128. 
Dohmen-Janssen C.M., W.N. Hassan, \& J.S. Ribberink, 2001, Mobile-bed effects in oscillatory sheet flow. J. Geophys. Res., 106, 27103-27115.

Dohmen-Janssen, C. M., D. F. Kroekenstoel, W. N. Hassan, and J. S. Ribberink, 2002, Phase lags in oscillatory sheet flow: experiments and bed load modeling. Coastal Engineering, 46, $61-87$.

Dohmen-Janssen C.M., \& D.M. Hanes, 2002, Sheet flow dynamics under monochromatic nonbreaking waves. J. Geophys. Res., 107, 3149, doi:10.1029/2001JC991945.

Dohmen-Janssen C.M., \& D.M. Hanes, 2005, Sheet flow and suspended sediment due to wave groups in a large wave flume. Cont. Shelf Res, 25, 333-347.

Dong, P. \& K. Zhang, 2002, Intense near-bed sediment motions in waves and currents. Coastal Engineering, 45, 75-87.

Drake, T.G., \& J. Calantoni, 2001, Discrete particle model for sheet flow sediment transport in the nearshore. J. Geophys. Res., 106, 19859-19868.

Elgar, S., 1987, Relationships involving third moments and bispectra of a harmonic process. IEEE Trans. on Acoustics, Speech, and Signal Processing 35, 1725-1726.

Elgar, S., R. T. Guza, and M. H. Freilich, 1988, Eulerian measurements of horizontal accelerations in shoaling gravity waves. J. Geophys. Res., 93, 9261-9269.

Elgar S., E.L. Gallagher, \& R.T. Guza, 2001, Nearshore sandbar migration. J. Geophys. Res., 106, 11623-11627.

Gallagher E.L., S. Elgar, \& R.T. Guza, 1998, Observations of sand bar evolution on a natural beach. J. Geophys. Res., 103, 3203-3215. 
Fredsøe, J., 1984, Turbulent boundary layer in wave-current motion. J. Hydr. Eng., ASCE, 110, 1103-1120.

Grant, W.D., \& O.S. Madsen, 1979, Combined wave and current interaction with a rough bottom. J. Geophys. Res., 84, 1797-1808.

Henderson S.M., J.S. Allen, \& P.A. Newberger, 2004, Nearshore sandbar migration by an eddydiffusive boundary layer model. J. Geophys. Res., 109, C06024, doi:10.1029/2003JC002137.

Hoefel, F., \& S. Elgar, 2003, Wave-induced sediment transport and sandbar migration. Science, 299, 1885-1887.

Hsu, T.-J., J.T. Jenkins, \& P.L.-F. Liu, 2004, Two-phase sediment transport: sheet flow of massive particles. Proc. Roy. Soc. Lond. (A), 460, doi:10.1098/rspa.2003.1273.

Hsu, T.-J., \& D.M. Hanes, 2004, The effect of wave shape on sheet flow sediment transport. $J$. Geophys. Res., 109, C05025, doi:10.1029/2003JC002075.

Hsu, T.-J. \& P. L.-F., Liu, 2004, Toward modeling turbulent suspension of sand in the nearshore. J. Geophys. Res., 109, C06018, doi:10.1029/2003JC002240.

Hsu, T.-J. \& Raubenheimer, B., 2005, A numerical and field study on inner-surf and swash sediment transport. Continental Shelf Res., submitted.

Jaluria, Y., \& K.E. Torrance, 1986, Computational heat transfer, Hemisphere Publishing Corporation, New York.

Justesen, P., 1988, Prediction of turbulent oscillatory flow over rough beds. Coastal Engineering, $12,257-284$. 
Li, Z., \& A. G. Davies, 1996, Toward predicting sediment transport in combined wave-current flow. J. Wtrway., Port, Coast. and Ocean Engrg., 122, 157.

Nairn, R.B. \& H.N. Southgate, 1993, Deterministic profile modelling of nearshore processes Part 2. Sediment transport and beach profile development. Coastal Engineering, 19, 57-96.

Nielsen, P., 1992, Coastal Bottom Boundary Layers and Sediment Transport, World Scientific, Singapore.

Nielsen, P., and D. P. Callaghan, 2003, Shear stress and sediment transport calculations for sheet flow under waves. Coastal Engineering, 47, 347-354.

Rodi, W., 1993, Turbulence models and their application in Hydraulics - A state of the art review. IAHR, Delft.

Ribberink, J.S., \& A.A. Al-Salem, 1994, Sediment transport in oscillatory boundary layer in cases of rippled beds and sheet flow. J. Geophys. Res., 99, 12707-12727.

Ribberink, J.S., 1998, Bed-load transport for steady flows and unsteady oscillatory flows. Coastal Engineering, 34, 59-82.

Roelvink, J.A., \& M.J.F. Stive, 1989, Bar generating cross-shore flow mechanisms on a beach. $J$. Geophys. Res., 94, 4785-4800.

Soulsby, R.L., L. Hamm, G. Klopman, D. Myrhaug, R.R. Simons, and G.P. Thomas, 1993, Wavecurrent interaction within and outside the bottom boundary layer. Coastal Engineering, 21, 41-69.

Swart, D. H., 1974, Offshore sediment transport and equilibrium beach profile. Delft Hydr. Lab. Publ., No.131, Delft Hydraulics, The Netherlands. 
Thornton, E., R. Humiston, \& W. Birkemeier, 1996, Bar-trough generation on a natural beach. $J$. Geophys. Res, 101, 12097-12110.

Traykovski P., A.E. Hay, J.D. Irish, \& J.F. Lynch, 1999, Geometry, migration, and evolution of wave orbital ripples at LEO-15. J. Geophys. Res, 104, 1505-1524.

Trowbridge, J. \& O.S. Madsen, 1984, Turbulent wave boundary layers 2. Second-order theory and mass transport. J. Geophys. Res., 89, 7999-8007.

Trowbridge, J. \& D. Young, 1989, Sand transport by unbroken waves under sheet flow conditions. J. Geophys. Res., 94, 10971-10991. 


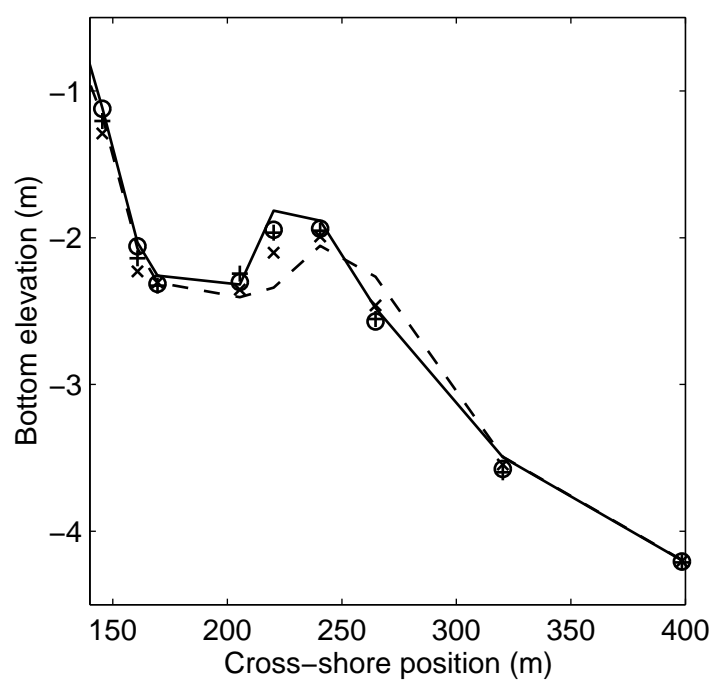

Figure 1: Bottom elevation (i.e., bed level relative to mean sea level) versus cross-shore position observed September 22 (dashed curve) and September 27 (solid curve) 1994. Symbols are model predictions of the September 27 profile initialized with the September 22 profile and driven with near-bottom wave-orbital (i.e., demeaned) velocities observed between 1900 September 22 and 2200 September 27. Crosses (x) are the quasi-steady model (8) with a wave friction factor $f_{w}=$ 0.01 , plusses $(+)$ are the second-order single-phase flow model (1-2) with a mixing-length closure $\left(K_{s}=14 d\right)$, and circles are the second-order model with $k-\epsilon$ closure $\left(K_{s}=25 d\right)$. The quasisteady model has moderate model skill $(M=0.34)$, whereas the second-order model with mixing length closure has higher skill ( $M=0.57)$. The highest skill ( $M=0.69$, circles) is obtained using $k-\epsilon$ closure in the second-order model. Average (3-hr) bottom elevations were obtained with altimeters colocated with pressure gages and current meters at the cross-shore positions with symbols [Gallagher et al., 1998]. Two additional current meters (not shown) without colocated altimeters were deployed near the bar crest. 


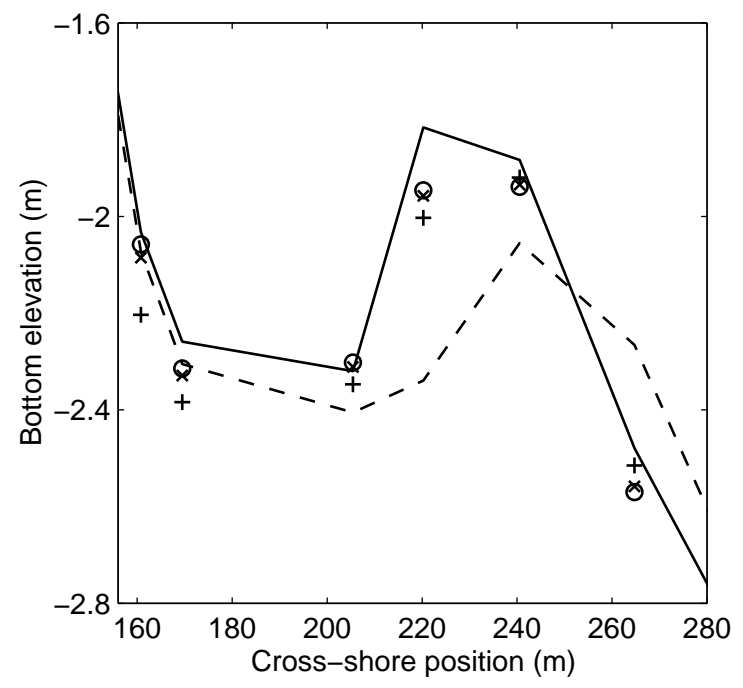

Figure 2: Bottom elevation (i.e., bed level relative to mean sea level) versus cross-shore position observed September 22 (dashed curve) and September 27 (solid curve) 1994 near the sandbar crest. Symbols are predictions of the September 27 profile (initialized with the September 22 profile) with only the wave-induced component of transport (second-order model with $k-\epsilon$ closure, $K_{s}=25 d$, circles) and with both wave- and mean-current- ((12) and (9), with $f_{c}=0.02$, crosses; $f_{c}=0.04$, plusses) induced transport components. 


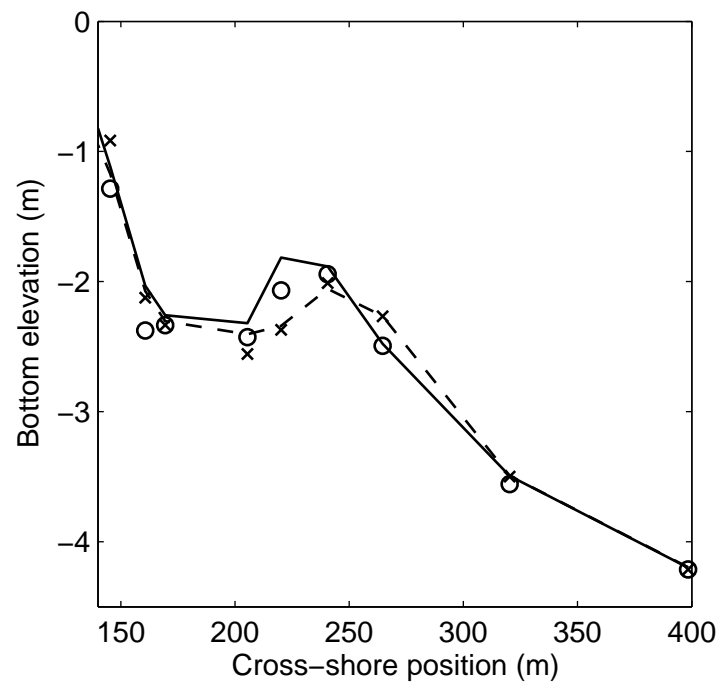

Figure 3: Bottom elevation (i.e., bed level relative to mean sea level) versus cross-shore position observed September 22 (dashed curve) and September 27 (solid curve) 1994. Symbols are predictions of the September 27 profile (initialized with the September 22 profile) from the energetics model [Gallagher et al., 1998] (crosses, $M=-0.1$ ), and from the EEFF model (13) (circles, $M=0.25$, with $\left.C_{w}=0.0046, C_{c}=0.0053\right)$. 


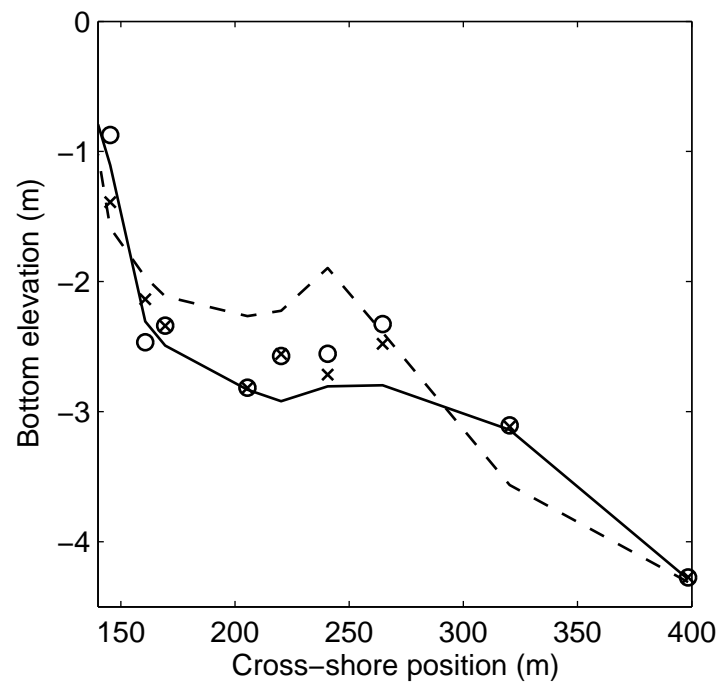

Figure 4: Bottom elevation (i.e., bed level relative to mean sea level) versus cross-shore position observed October 10 (dashed curve) and October 15 (solid curve) 1994. Symbols are predictions of the October 15 profile (initialized with the October 10 profile) from the energetics model [Gallagher et al., 1998] (crosses, $M=0.6$ ), and from the EEFF model (13) (circles, $M=0.55$, with $\left.C_{w}=0.0046, C_{c}=0.0053\right)$. 

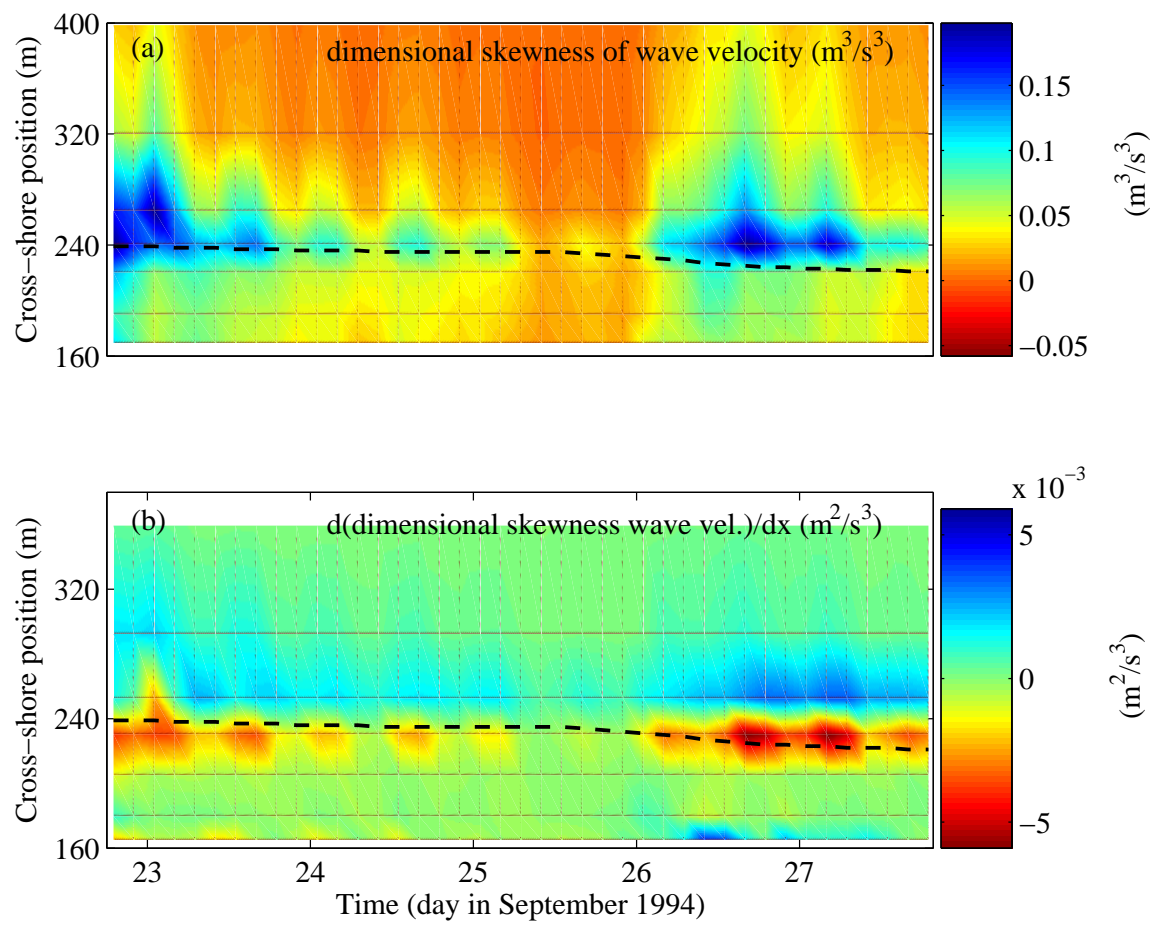

Figure 5: Contours (color scale at right) of (a) mean cubed oscillatory velocity $\left[\left\langle\tilde{U}_{0}^{3}(t)\right\rangle\right.$, the dimensional skewness] and (b) cross-shore gradient of dimensional skewness $\left[\partial\left\langle\tilde{U}_{0}^{3}(t)\right\rangle / \partial x\right]$ as a function of cross-shore position and time. The dashed curves indicate the approximate location of the bar crest. 

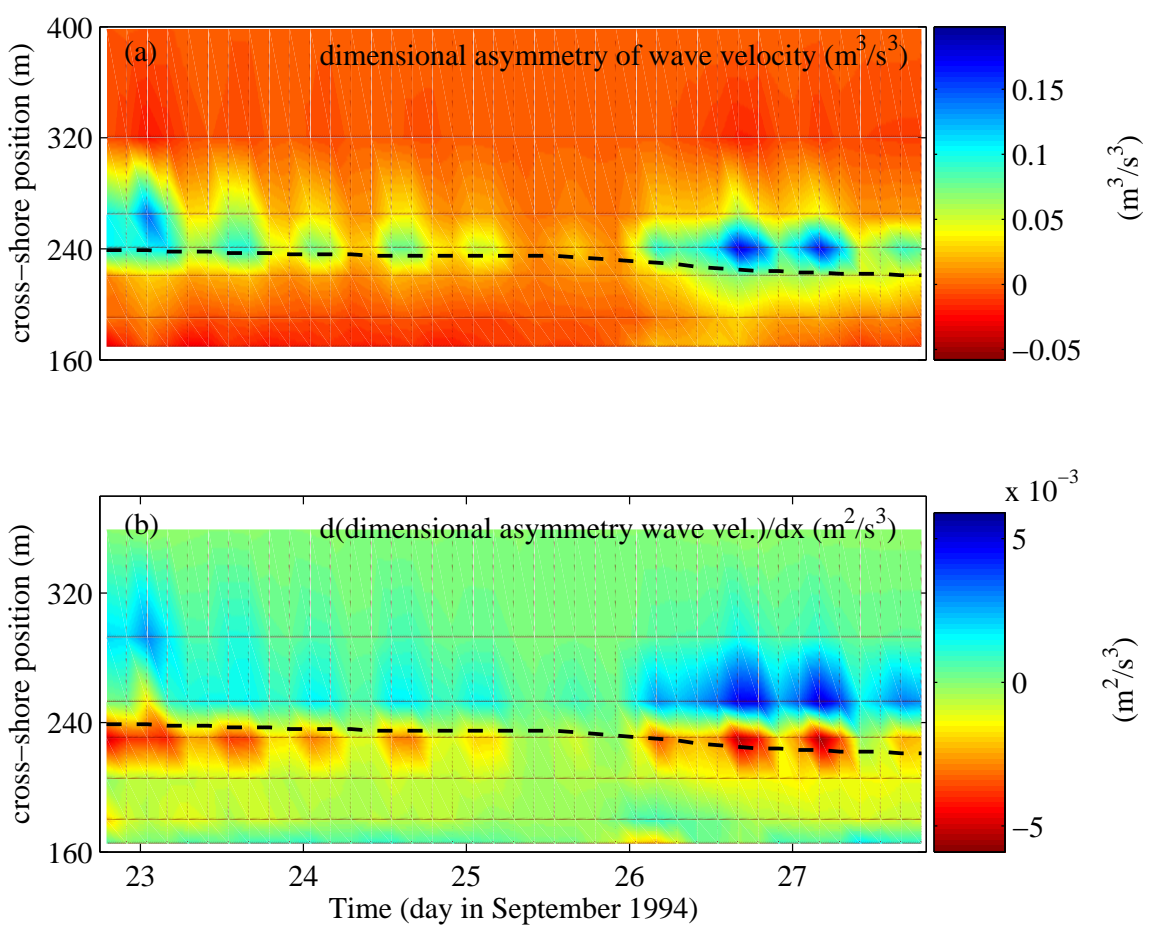

Figure 6: Contours (color scale at right) of (a) oscillatory velocity (dimensional) asymmetry (the mean of the cube of the Hilbert transform of the velocity time series [Elgar, 1987]) and (b) crossshore gradient of dimensional asymmetry as a function of cross-shore position and time. The dashed curves indicate the approximate location of the bar crest. 